\title{
No evidence for genetic differentiation of the mussel Mytilus galloprovincialis between lagoons and the seaside
}

\author{
${ }^{1}$ Jean-Pierre Škalamera ${ }^{1, *}$, François Renaud ${ }^{1}$, Michel Raymond ${ }^{2}$, Thierry de Meeûs ${ }^{1, * *}$ \\ ${ }^{1}$ Centre d'Etudes sur le Polymorphisme des Micro-organismes (CEPM), UMR CNRS/IRD 9926, 911 avenue d'Agropolis, \\ BP 5045, F-34032 Montpellier Cedex 01, France \\ ${ }^{2}$ Institut des Sciences de L'Evolution, UMR 5554, Laboratoire de Génétique et Environnement, Université Montpellier II, \\ Place E. Bataillon, F-34095 Montpellier Cedex 05, France
}

\begin{abstract}
Twelve locations of Mytilus galloprovincialis were sampled in lagoons and along the seaside in southern France. Lagoons represent a habitat with widely varying ecological conditions. Each lagoon has its own characteristic range of salinities and temperatures which fluctuate throughout the year. We studied several fundamental parameters of the population genetics of $M$. galloprovincialis at 8 enzymatic loci (genetic differentiation between locations, heterozygote deficits, selection, linkage disequilibrium) and investigated whether they are influenced by the high spatial and temporal instability of the lagoons (brackish water). In contrast to what could be expected based on the corresponding literature, we found no evidence for genetic differentiation, either among lagoons or between lagoons and the seaside. There was, thus, no evidence of selection on any of the loci studied.
\end{abstract}

KEY WORDS: Population genetics · Lagoons - Gene flow · Allozymes · Selection - Mussels

\section{INTRODUCTION}

Lagoons of the Gulf of Lions (Mediterranean, France) are shallow with depths ranging between 1 and 3 m (Quignard \& Zaouali 1980, Bourquard 1985). Ecological factors vary strongly within and among lagoons. Some lagoons have freshwater inflow from creeks, and in all lagoons salinity differs locally due to subterranean freshwater inflow. In addition, the amount of freshwater inflow varies with season. Marine water influences to some extent the salinity of lagoons by seeping through the barriers, as their sediment composition does not totally prevent water exchange. But most of the water exchange with the seaside is limited to narrow channels. Even though the tide is low in the Mediterranean, tide currents and cur-

\footnotetext{
- Present address: Universitaet Basel, Zoologisches Institut, Rheinsprung 9, 4051 Basel, Switzerland

"Addressee for correspondence.

E-mail: demeeus@cepm.mpl.orstom.fr
}

rents triggered by winds transport marine water into the lagoons (Bourquard 1985), leading to measurable changes in salinity and temperature. In each lagoon, the salinity gradient between the channel connecting it with the seaside and its freshwater inputs is stable although salinity can vary considerably. Benthic communities differ according to these salinity ranges.

Few studies have been done up until now on the population genetics in lagoons. In the Mediterranean only 2 bivalves (Ruditapes aureus and $R$. decussatus) from 1 lagoon (Etang de Thau) have been analysed (Borsa \& Thiriot-Quiévreux 1990, Borsa et al. 1991). Studying the genetic structure of oyster population of lagoons of southern Texas, USA, King et al. (1994) found differentiation between lagoons, a result of importance for fishery and conservation.

Compared with lagoons, the seaside has rather stable ecological factors (temperature or salinity). One could thus expect to find (1) a genetic differentiation between lagoons and seaside and (2) a higher genetic heterogeneity within lagoons for species inhabiting both environments. 
Mytilus galloprovincialis (Lmk) displays a wide distribution and it is found from the Mediterranean Sea to the Atlantic Ocean and the English Channel. Bivalve life history could illustrate a panmictic model: gametes are released in the sea before an apparent random external fertilisation. After a 3 to $7 \mathrm{wk}$ long planktonic stage (Bayne 1976) during which larvae are probably dispersed by currents, an apparently random settlement occurs. Paradoxically, many studies concerning allozyme variability in marine bivalves revealed local heterozygote deficiencies (see Zouros \& Foltz 1984 for review). On the other hand numerous studies have shown evidences for selection on electrophoretic loci in bivalves (Koehn \& Mitton 1972, Koehn et al. 1976, 1980, Koehn 1978, Gartner-Kepkay et al. 1983, Singh \& Green 1984, Diehl et al. 1985, Hawkins et al. 1986, McDonald \& Siebenaller 1989, Gaffney 1990, Karl \& Avise 1992, David et al. 1995). In this study we investigate the population genetics of 8 polymorphic enzymatic loci in $M$. galloprovincialis from 12 sites of the Gulf of Lions. We examine population differentiation and heterozygote deficiency, and look for possible effects of selection on allelic frequencies and on linkage disequilibria. Special interest is given to the Lap locus as several studies have reported selection on an allele at this locus (Koehn et al. 1976, 1980, Hilbish \& Koehn 1985, McDonald \& Siebenaller 1989).

\section{MATERIALS AND METHODS}

A total of 12 samples (50 individuals each) of the bivalve Mytilus galloprovincialis were taken along the French coast during the spring of 1996 (Fig. 1). Special interest was given to the sampling of populations of lagoons. Salinity (Fig. 1) was determined using a manual refractometer Atago S/MILL. Four samples were collected in the zone where a channel coming from a lagoon flows into the sea. An additional 7 samples were taken from 5 different lagoons connected to these channels. In January 1997 an additional sample was taken further away from the lagoons at Banyuls-surMer for comparison (BYM, Fig. 1). Starch gel electrophoresis was performed in accordance with the protocol described in Pasteur et al. (1988). A total of 8 loci with known polymorphism was chosen (Beaumont et al. 1989, Coustau et al. 1991). These loci were esterase (Est-D, EC 3.1.1.1), glucose phosphate isomerase (Gpi, EC 5.3.1.9), isocitrate dehydrogenase (Idh, EC 1.1.1.42), mannose-6-phosphate isomerase ( $M p i$, EC 5.3.1.8), octopine dehydrogenase $(\mathrm{Odh}, \mathrm{EC}$ 1.5.1.11), and the peptidases Pep-A (EC 3.4...-, substrate Val-Leu), Pep$D$ (EC 3.4.-.-, substrate Phe-Pro), leucine aminopeptidase (Lap, EC 3.4.11.1). We also tried to study the phosphoglucomutase locus (Pgm, EC 2.7.5.1), but obtained only unstable and non-repeatable phenotypes. It was therefore excluded from the study. All alleles were numbered according to their increasing anodal mobility.

Linkage disequilibria were tested by the exact test for genotypic linkage disequilibrium of the program GENEPOP V3.1 (Raymond \& Rousset 1995).

Canonical Correspondence Analysis (CCA) was carried out to study population structure, using the CANOCO program (Ter Braak 1986, 1987, 1995). Genotypes of individuals were utilised for the CCA. Only individuals for which all loci could be scored were included in the analysis. As a result all individu-

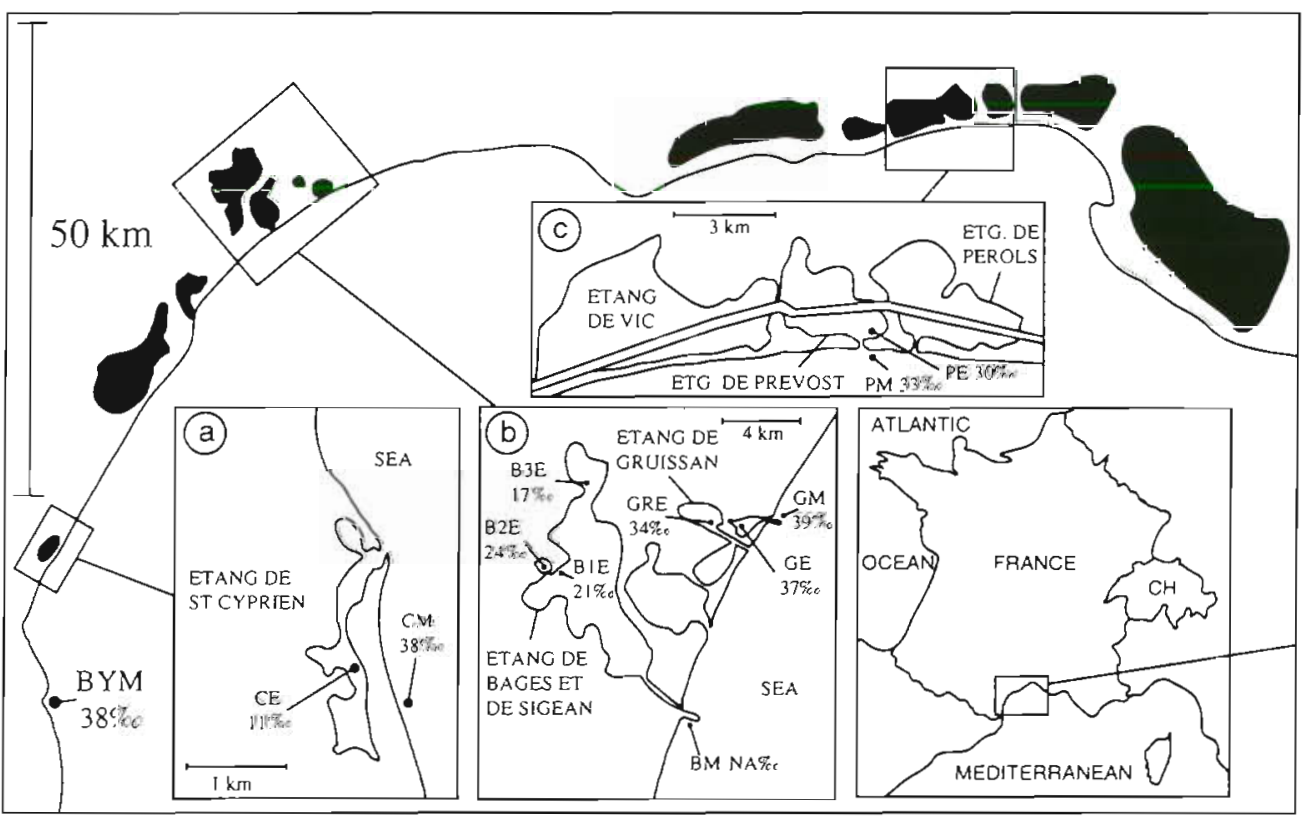

Fig. 1. Sampling sites of Mytilus galloprovincialis in southern France. Lagoon sample abbreviations end with $E$, seaside abbreviations with M. (a) Etang (Lagoon) de St. Cyprien: CE, CM. (b) Etang de Bages et de Sigean: B1E, B2E, B3E. Port-la-Nouvelle: BM. Etang de Gruissan: GM, GRE. Etang de Grazel: GE. (c) Etang de Prévost: PE, PM. Banyuls-sur-Mer: BYM. NA: not available 
als from Banyuls-sur-Mer (BYM, Fig. 1) had to be excluded, since Pep-D could not be analysed in this sample for technical reasons. For this CCA analysis, genotypes with a frequency lower than $5 \%$ of the total number of individuals were excluded to avoid a bias due to rare alleles. The significance of the canonical axes was tested with a Monte Carlo permutation test (Ter Braak 1987, 1995). This also allowed estimation of the $95 \%$ confidence intervals of the centroid of each population.

Genetic differentiation was studied with $F$-statistics (Wright 1965). The Program Genepop V3.1 was used to estimate Weir \& Cockerham's (1984) unbiased estimators of $F$-statistics ( $f$ for $F_{i s}$ and $\theta$ for $F_{s t}$ ). This program also performs the score test ( $U$-test) (Rousset \& Raymond 1995) to test if heterozygote deficiencies are significant. This test provides an exact p-value for less than 5 alleles, following the enumeration method described by Louis \& Dempster (1987), or an unbiased estimate of this probability for more alleles through the Markov chain method (Guo \& Thompson 1992). For population differentiation an unbiased estimate of the p-value of a $\log$-likelihood $(G)$ based exact test is performed (Goudet et al. 1996). As a global test over all loci we also used the permutation procedure of individuals among samples (10000 permutations) with the program Fstat-V1.2 (Goudet 1996).

The correlation between genetic differentiation and salinity differences of pairs of samples was analysed by means of Mantel tests (Manly 1985) computed with the software nPSTAT V2.95 (PRAXEME R\&D ${ }^{\mathrm{TM}}$ ).

To compare the level of heterozygote deficiencies between the seaside and lagoons we used permutation tests performed by the software npSTAT V2.95 (PRAXEME R\&DTM). A 2-sample test was used to study the differences between the multilocus estimates of $F_{i s}$ (5 measures in the sea, 7 measures in lagoons). A paired sample test was used to analyse the difference between the multi-sites estimates of $F_{\text {is }}$ ( 8 measures). The possible link between $f$ and salinity was also studied using a Spearman rank correlation 2-tailed tests performed with the same software. The estimates of null allele frequencies explaining heterozygote deficits were calculated following Brookfield's (1996) procedure, assuming all missing data correspond to null homozygotes.

Multiple testing enhances type I error. We thus applied the sequential Bonferroni procedure when necessary (Holm 1979) (see Rice 1989).

\section{RESULTS}

The allelic frequencies of the 8 enzymatic loci studied are given in Table 1.

\section{Linkage disequilibrium}

The statistical independence of loci was not rejected for any pair of loci at the Bonferroni level (for 28 pairs of loci $\alpha^{\prime}=0.05 / 28=0.00179$ ).

\section{Canonical Correspondence Analysis}

Fig. 2 shows a graphic representation of the results. The centroid of each population is surrounded by its $95 \%$ confídence interval. A Monte Carlo test permuting individuals among population showed that the axes of the CCA could not explain differentiation between populations (eigenvalue $=0.016, p=0.25$ for Axis 1, eigenvalue $=0.014, p=0.36$ for Axis 2, eigenvalue $=0.012, p=0.71$ for Axis 3 for 1000 permutations). This can be seen in the overlapping circles of the $95 \%$ confidence intervals. Nevertheless, the overall test on the first 4 axes was significant ( $p=0.04$ ), indicating an overall structure that cannot be explained in a simple way

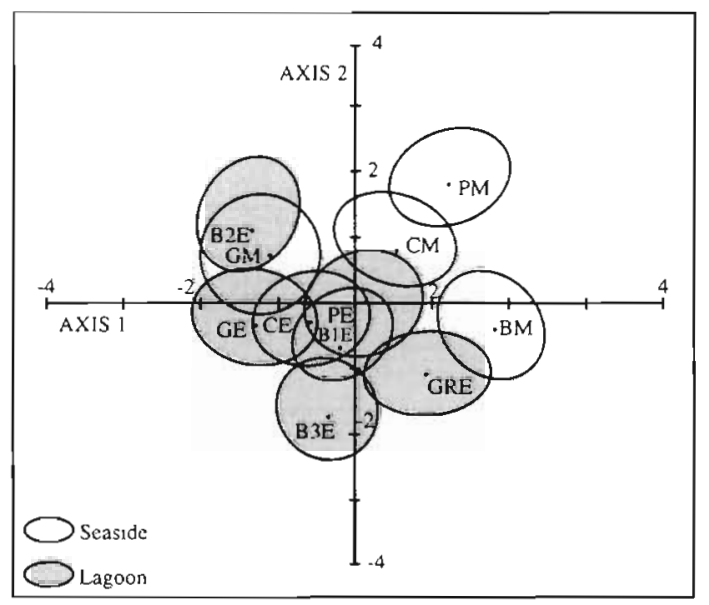

Fig. 2. Graphical representation of the results of Canonical Correspondence Analysis. Centroids of every population are surrounded by the $95 \%$ interval of confidence of their position. For abbreviations see Fig. 1

\section{F-statistics}

Overall loci, pairwise comparisons between samples were not significant at the Bonferroni level for the 66 pairs, $\alpha^{\prime}=0.05 / 66=0.0007$.

A comparison of the pooled lagoon samples with the pooled seaside samples for every locus gave no significance at the Bonferroni level $\left(\alpha^{\prime}=0.05 / 8=0.006\right)$ and no $F_{s t}$ estimates higher than 0.003 . Furthermore, overall loci did not provide a significant result either $(\theta=$ $0.001 ; p=0.107$ ). 
Table 1. Mytilus galloprovincialis. Allele frequencies of the investigated loci. Alleles are numbered according to their increasing anodal mobility. Sampling sites as in Fig. 1. N: number of individuals analysed. Enzymes as in 'Material and methods'

\begin{tabular}{|c|c|c|c|c|c|c|c|c|c|c|c|c|}
\hline \multirow[t]{2}{*}{ Enzyme } & \multicolumn{12}{|c|}{ Sample site } \\
\hline & $P E$ & PM & CE & $\mathrm{CM}$ & $\mathrm{B} 1 \mathrm{E}$ & B2E & $\mathrm{BM}$ & B3E & GRE & $\mathrm{GE}$ & $\mathrm{GM}$ & BYM \\
\hline \multicolumn{13}{|l|}{ IDH } \\
\hline $\mathrm{N}$ & 50 & 50 & 50 & 50 & 50 & 50 & 50 & 50 & 50 & 50 & 50 & 50 \\
\hline 1 & 0.07 & 0.05 & 0.11 & 0.11 & 0.11 & 0.06 & 0.09 & 0.13 & 0.15 & 0.06 & 0.08 & 0.04 \\
\hline 2 & 0.92 & 0.92 & 0.88 & 0.82 & 0.89 & 0.94 & 0.91 & 0.85 & 0.83 & 0.92 & 0.92 & 0.92 \\
\hline 3 & 0.01 & 0.03 & 0.01 & 0.07 & 0 & 0 & 0 & 0.02 & 0.02 & 0.02 & 0 & 0.04 \\
\hline \multicolumn{13}{|l|}{ MPI } \\
\hline$N$ & 50 & 50 & 50 & 50 & 50 & 50 & 50 & 50 & 50 & 50 & 50 & 50 \\
\hline 1 & 0.98 & 0.97 & 0.97 & 0.93 & 0.98 & 0.94 & 0.95 & 0.92 & 0.95 & 0.94 & 0.94 & 0.98 \\
\hline 2 & 0.02 & 0.03 & 0.02 & 0.07 & 0.01 & 0.06 & 0.04 & 0.07 & 0.05 & 0.06 & 0.06 & 0.02 \\
\hline 3 & 0 & 0 & 0.01 & 0 & 0.01 & 0 & 0.01 & 0.01 & 0 & 0 & 0 & 0 \\
\hline \multicolumn{13}{|l|}{$\mathrm{ODH}$} \\
\hline$N$ & 50 & 50 & 50 & 50 & 50 & 50 & 50 & 50 & 50 & 50 & 50 & 50 \\
\hline 1 & 0.15 & 0.19 & 0.08 & 0.21 & 0.17 & 0.08 & 0.2 & 0.18 & 0.14 & 0.14 & 0.15 & 0.16 \\
\hline 2 & 0.2 & 0.17 & 0.23 & 0.21 & 0.24 & 0.19 & 0.19 & 0.19 & 0.28 & 0.25 & 0.31 & 0.27 \\
\hline 3 & 0.65 & 0.64 & 0.69 & 0.58 & 0.59 & 0.72 & 0.61 & 0.63 & 0.58 & 0.6 & 0.54 & 0.57 \\
\hline 4 & 0 & 0 & 0 & 0 & 0 & 0.01 & 0 & 0 & 0 & 0.01 & 0 & 0 \\
\hline \multicolumn{13}{|l|}{ GPI } \\
\hline $\mathrm{N}$ & 50 & 50 & 50 & 50 & 50 & 50 & 50 & 50 & 50 & 49 & 50 & 50 \\
\hline 1 & 0.02 & 0.04 & 0.04 & 0.05 & 0 & 0.06 & 0.03 & 0.03 & 0.01 & 0.031 & 0.01 & 0.02 \\
\hline 2 & 0.79 & 0.75 & 0.69 & 0.79 & 0.84 & 0.8 & 0.77 & 0.85 & 0.79 & 0.776 & 0.78 & 0.79 \\
\hline 3 & 0.19 & 0.15 & 0.22 & 0.09 & 0.14 & 0.12 & 0.17 & 0.1 & 0.16 & 0.163 & 0.14 & 0.14 \\
\hline 4 & 0 & 0.06 & 0.05 & 0.07 & 0.02 & 0.02 & 0.03 & 0.02 & 0.03 & 0.031 & 0.07 & 0.05 \\
\hline 5 & 0 & 0 & 0 & 0 & 0 & 0 & 0 & 0 & 0.01 & 0 & 0 & 0 \\
\hline \multicolumn{13}{|l|}{ PEP-A } \\
\hline$N$ & 50 & 50 & 50 & 50 & 50 & 50 & 48 & 50 & 50 & 50 & 50 & 47 \\
\hline 1 & 0.01 & 0 & 0 & 0 & 0.01 & 0.01 & 0 & 0 & 0 & 0.01 & 0.02 & 0.021 \\
\hline 2 & 0.17 & 0.22 & 0.13 & 0.16 & 0.23 & 0.08 & 0.219 & 0.23 & 0.16 & 0.15 & 0.12 & 0.17 \\
\hline 3 & 0.39 & 0.34 & 0.44 & 0.47 & 0.43 & 0.49 & 0.354 & 0.42 & 0.46 & 0.45 & 0.39 & 0.415 \\
\hline 4 & 0.25 & 0.22 & 0.3 & 0.21 & 0.24 & 0.23 & 0.271 & 0.22 & 0.26 & 0.21 & 0.33 & 0.266 \\
\hline 5 & 0.14 & 0.2 & 0.12 & 0.15 & 0.08 & 0.19 & 0.135 & 0.12 & 0.1 & 0.15 & 0.14 & 0.096 \\
\hline 6 & 0.04 & 0.02 & 0.01 & 0.01 & 0.01 & 0 & 0.021 & 0.01 & 0.02 & 0.03 & 0 & 0.032 \\
\hline \multicolumn{13}{|l|}{ EST-D } \\
\hline $\mathrm{N}$ & 49 & 50 & 50 & 49 & 50 & 49 & 50 & 50 & 50 & 49 & 50 & 50 \\
\hline 1 & 0.02 & 0.01 & 0.01 & 0 & 0.02 & 0.01 & 0.01 & 0.04 & 0.03 & 0.031 & 0.03 & 0.03 \\
\hline 2 & 0.939 & 0.9 & 0.95 & 0.929 & 0.93 & 0.878 & 0.92 & 0.93 & 0.95 & 0.939 & 0.92 & 0.92 \\
\hline 3 & 0.041 & 0.09 & 0.04 & 0.071 & 0.05 & 0.112 & 0.07 & 0.03 & 0.02 & 0.031 & 0.05 & 0.05 \\
\hline \multicolumn{13}{|l|}{ PEP-D } \\
\hline $\mathrm{N}$ & 50 & 50 & 50 & 50 & 50 & 50 & 50 & 50 & 48 & 39 & 45 & 0 \\
\hline 1 & 0.02 & 0.01 & 0.02 & 0.05 & 0.01 & 0.05 & 0 & 0.03 & 0.021 & 0 & 0.011 & - \\
\hline 2 & 0.07 & 0.14 & 0.11 & 0.06 & 0.07 & 0.09 & 0.09 & 0.05 & 0.188 & 0.077 & 0.067 & - \\
\hline 3 & 0.49 & 0.49 & 0.62 & 0.54 & 0.56 & 0.51 & 0.41 & 0.55 & 0.469 & 0.577 & 0.611 & - \\
\hline 4 & 0.28 & 0.24 & 0.19 & 0.23 & 0.26 & 0.24 & 0.37 & 0.29 & 0.229 & 0.244 & 0.244 & - \\
\hline 5 & 0.14 & 0.12 & 0.06 & 0.12 & 0.1 & 0.11 & 0.13 & 0.08 & 0.094 & 0.103 & 0.067 & - \\
\hline \multicolumn{13}{|l|}{ LAP } \\
\hline$N$ & 50 & 50 & 50 & 50 & 50 & 50 & 50 & 49 & 50 & 50 & 50 & 50 \\
\hline 1 & 0.01 & 0.02 & 0.06 & 0.04 & 0.05 & 0.04 & 0.01 & 0.02 & 0.04 & 0.01 & 0.02 & 0.07 \\
\hline 2 & 0.5 & 0.61 & 0.41 & 0.46 & 0.36 & 0.49 & 0.51 & 0.388 & 0.42 & 0.49 & 0.48 & 0.43 \\
\hline 3 & 0.43 & 0.27 & 0.43 & 0.4 & 0.43 & 0.36 & 0.43 & 0.51 & 0.46 & 0.41 & 0.44 & 0.37 \\
\hline 4 & 0.06 & 0.09 & 0.1 & 0.1 & 0.16 & 0.11 & 0.05 & 0.082 & 0.08 & 0.09 & 0.06 & 0.12 \\
\hline 5 & 0 & 0.01 & 0 & 0 & 0 & 0 & 0 & 0 & 0 & 0 & 0 & 0.01 \\
\hline
\end{tabular}

The Mantel test performed on $\theta$ over all loci and salinities was not significant $(G=0.96, p=0.17)$

There was a strong and highly significant heterozygote deficiency over all loci and populations $(f=0.09$, $\mathrm{p}=0)_{\text {; }}$ however, it was very variable among loci and among populations (Figs. $3 \& 4$ ).
No significant difference in the level of heterozygote deficiency could be found between seaside and lagoons among sites on the multilocus estimates (2sample permutation test, $\mathrm{p}=0.97$ ) or among loci in the multi-site estimates (permutation test for paired series, $\mathrm{p}=0.7$ ). The correlation between $f$ and salinity was not 


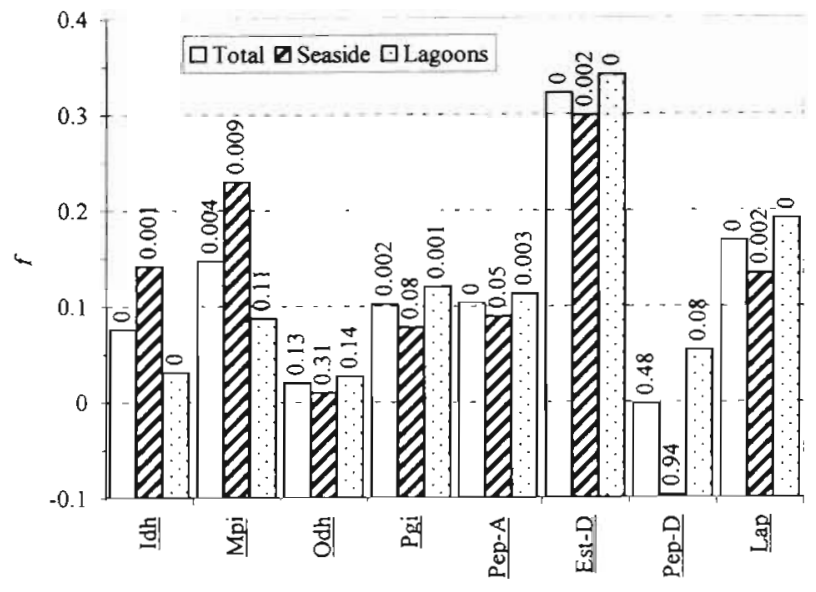

Fig. 3. Estimates of $F_{i s}(f)$ for each locus for all populations (Total), seaside samples (Seaside) and lagoon samples (Lagoons). The p-value for the significance of heterozygote deficiency is indicated above each bar. For locus abbreviations see 'Materials and Methods'

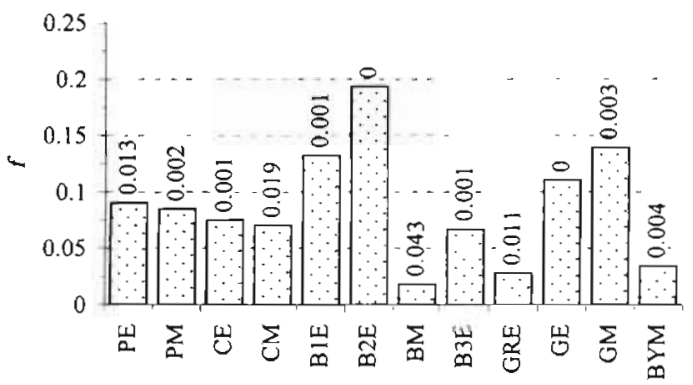

Fig. 4. $F_{\text {is }}$ estimates $(f)$ for each sample over all loci. The pvalue for the significance of heterozygote deficiency is indicated above each bar. For sample abbreviations see Fig. 1

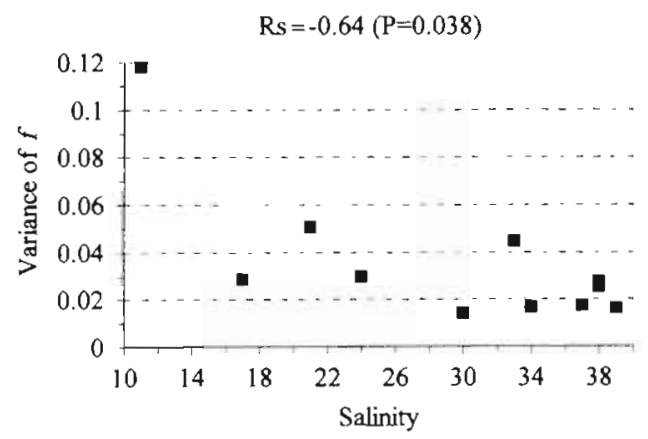

Fig. 5. Representation of the correlation between salinities (in $\mathrm{g} \% \mathrm{l})$ and the variance of $f\left(F_{i s}\right.$ estimate) among loci

significant (Spearman rank correlation $\mathrm{r}_{\mathrm{S}}=0.12, \mathrm{p}=$ 0.27 ). However, we found a significant negative correlation between the variance of $f$ among loci and salinity $\left(r_{S}=-0.64, p=0.038\right.$ ) (Fig. 5). Decreasing salinities correspond to larger differences in $f$ among loci.

The differentiation displayed by the Lap locus between pooled seaside samples and pooled lagoon samples was weak and not significant $(\theta=0.003 ; p=$ 0.0743 ). At this locus, differentiation is expected to occur between seaside and lagoon samples (Koehn et al. 1976, 1980, Hillbish \& Koehn 1985). Among the 34 possible paired comparisons between seaside and lagoon samples, 3 p-values (8.8\%) are below 0.05 . This is not significantly different to what was expected following the null hypothesis with a $5 \%$ type I error (binomial probability $\mathrm{p}=0.24$ ). The Mantel test comparing $\theta$ and salinity differences between the different pairs of samples $(G=0.04, \mathrm{p}=0.49) \mathrm{did}$ not provide any further evidence for selection at the Lap locus.

\section{DISCUSSION AND CONCLUSIONS}

\section{Genetic structure of the populations}

Studying the population structure of oysters in Lagoons of Texas, King et al. (1994) found significant differentiation with a mean $F_{s t}$ estimate of 0.164 . The lagoons of Texas are up to 10 times older than those involved in the present study. Estimates range from 20000 to 50000 yr for the oldest lagoons, but this system is also very dynamic due to hurricanes and can change a lot over time (King pers. comm.).

There are several studies (e.g. Quesada et al. $1995 \mathrm{a}, \mathrm{b})$ that demonstrate major intraspecific genetic changes in Mytilus galloprovincialis associated with sharp ecological changes.

Our study did not find strong evidence of genetic differentiation, either between lagoon samples, or in comparisons of seaside with lagoon samples. Summarising the graph of the CCA (Fig. 2), some population pairs can differentiate significantly, but due to the large data set, we were able to show that the other populations occupy intermediate positions independent of geography, or of the ecology of the different lagoons and the sea. The fact that the CCA found no axis differentiating between populations, but that it still found an overall significant differentiation for the first 4 axes, indicates that differentiation exists but follows factors that were not taken into account (i.e. unknown). Several reasons could prevent the populations from differentiating strongly. First of all, the history of the lagoons is very recent. Also, selecting factors could vary between years. In addition, larvae from seaside populations can settle in lagoons, and even larval exchange between lagoons is possible. Bourquard (1985) describes several meteorological situations which could lead to fish larvae exchange between lagoons. Another important factor is mussel farming in some lagoons and at the seaside. Breeding stock is being exchanged between different sites and with 
other Mediterranean countries (Italy) (Renaud pers. obs.).

Most studies investigating allozymes of bivalves found heterozygote deficiencies. Nevertheless, comparison between studies is difficult as calculations and tests differ. To overcome this problem Raymond et al. (1997) re-analysed large data sets of mussels from the Mytilus edulis complex. They found that in the existing literature heterozygote deficiencies were rather underestimated. In our samples heterozygote deficiencies varied greatly between loci and sampling sites. The Wahlund effect could be one explanation, though if this were the case, we should find a higher level of heterozygote deficiency in lagoons because of their higher ecological heterogeneity (coexistence of different cohorts selected under different conditions): however, we did not find this in our study. Furthermore, pooling seaside samples with lagoon samples does not increase $F_{i s}$ estimates (no evidence for a Wahlund effect). Also, influences from lagoons or coastal sites with mussel farming cannot be excluded. As we could not differentiate between cohorts, interference by a temporal Wahlund effect should be considered as a possible explanation, as suggested in studies on other marine molluscs (Johnson \& Black 1984, Borsa et al. 1991, Lewis \& Thorpe 1994, David et al. 1995). Null alleles could partly explain the heterozygote deficiencies. The number of expected null homozygotes for each locus (using Brookfield's [1996] procedure) is always higher than the observed one, except for Pep-A (data not shown), suggesting that null alleles are at a lower frequency than that required to compensate all the heterozygote deficiency. A clear tendency does not emerge from the correlation between $F_{i s}$ and the number of putative null homozygotes (expected to be positively correlated) in each population (Spearman $r_{S}=$ $-0.12, \mathrm{p}=0.71)$ or each locus $\left(r_{S}=0.012, \mathrm{p}=0.5\right)$. Nevertheless, this hypothesis cannot be fully excluded, nor can Chakraborty's (1989) hypothesis of molecular imprinting.

\section{Selection}

In a review on the hybridisation of Mytilus galloprovincialis with $M$. edulis at the Atlantic coast, Gardner (1994) describes $M$. galloprovincialis as less tolerant to estuarine conditions (desalinisation and fluctuations of salinity). In Mediterranean lagoons, on the other hand, we found M. galloprovincialis at very low salinities at sites where strong fluctuations of salinity are known to occur.

Koehn et al. $(1976,1980)$ showed selection for the Lap-94 allele of Mytilus edulis along the east coast of the USA. McDonald \& Siebenaller (1989) found the same allele in $M$. trossulus. Its frequency differed between marine and estuarine samples on the west coast of the USA (Oregon). Even though we sampled sites with low and variable salinity, we did not find evidence for selection either on any Lap allele or on the other loci of M. galloprovincialis. As we had no samples from the USA, we could not check whether the Lap-94 allele is present in $M$. galloprovincialis. It could be that the Lap-94 allele does not exist in $M$. galloprovincialis. Indeed, in a world-wide study of Mytilus sp., McDonald et al. (1991) did not find this allele in $M$. galloprovincialis from the northern hemisphere. Nevertheless, the fact that the variance of $f$ among loci decreases with salinity may be an indication of some selective factors affecting differentially the different loci in time or in space in lagoons (corresponding to our lowest salinities) while acting homogeneously within the seaside (our highest salinities). The influence of salinity on allozymes does not appear as a rule in $M$. galloprovincialis as for other bivalves (Michinina \& Rebordinos 1997).

Several investigations were made to study linkage disequilibria in Mytilus edulis (Mitton \& Koehn 1973. Ahmad \& Hedrick 1985, Beaumont 1994) with contradictory conclusions. Here, we found no evidence for linkage disequilibrium at any pair of loci. Thus, we found no indication that the heterogeneous environments where mussels were sampled selected for any linkage disequilibrium between the different loci.

Balancing selection acting on allozymes would be expected to act in different directions in the sea and in lagoons. Our results do not confirm the existence of selective factors such as were suggested by other works (e.g. Karl \& Avise 1992).

In conclusion, a genetic heterogeneity is displayed between some pairs of Mytilus galloprovincialis samples but without any clear connection to geographical distances, degree of isolation or ecological factors (different lagoons and seaside) (Fig. 2). The sampled area does not correspond to a hybrid zone between different mussel taxa (Sanjuan et al. 1994), which could have partly helped to interpret our results. Samples were also large enough to prevent type II errors. According to Goudet et al. (1996) simulations, a $F_{s l}$ as low as 0.026 should have been detected at the 0.05 significance level in almost all cases with our sampling design. It is possible that artificial migrations caused by man partly explain our results (Wahlund effects and lack of coherent differentiation). However, the large variances observed from one site to another, and from one locus to another, remain difficult to interpret and it is probable that, as suggested by Raymond et al. (1997), numerous different factors have to be considered, many of which have not yet been identified and, thus, are difficult to take into account. 
Acknowledgements. The stay of J.P.S in France was possible due to the financial aid of his parents Eva and Branimir and fundings by the 'Jubiläumsstiftung der Basellandschaftlichen Kantonalbank, Liestal' and the ERASMUS program of the EU. We thank J. Goudet for his help. We thank P. Borsa for useful comments on the manuscript. This is ISEM contribution no. 99013.

\section{LITERATURE CITED}

Ahmad M, Hedrick PW (1985) Electrophoretic variation in the common mussel, Mytilus edulis: random association of alleles at different loci. Heredity 55:47-51

Bayne BL (1976) Marine mussels, their ecology and physiology. Cambridge University Press, Cambridge

Beaumont AR (1994) Linkage studies in Mytilus edulis, the mussel. Heredity 72:557-562

Beaumont AR, Seed R, Garcia-Martinez P (1989) Electrophoretic and morphometric criteria for the identification of the mussels Mytilus edulis and M. galloprovincialis. In: Ryland JS, Tyler PA (eds) Reproduction, genetics, and distribution of marine organisms. Olsen \& Olsen, Fredensborg, p 251-258

Borsa P, Thiriot-Quiévreux C (1990) Kariological and allozymic characterisation of Ruditapes philippinarum, $R$ aureus and $R$. decussatus (Bivalvia, Veneridae). Aquaculture 90:209-227

Borsa P, Zainuri M, Delay B (1991) Heterozygote deficiency and population structure in the bivalve Ruditapes decussatus. Heredity $66: 1-8$

Bourquard C (1985) Structure et mécanisme de mise en place, de maintien et d'évolution des peuplements ichthyiques lagunaires du Golfe du Lion. Thèse de Doctorat, Université de Montpellier II, France

Brookfield JFY (1996) A simple method for estimating null allele frequency from heterozygote deficiency. Mol Ecol 5: $453-455$

Chakraborty R (1989) Can molecular imprinting explain heterozygote deficiency and hybrid vigour? Genetics 122 : $713-717$

Coustau C, Renaud F, Delay B (1991) Genetic characterization of the hybridization between Mytilus edulis and $M$. galloprovincialis on the Atlantic coast of France. Mar Biol 111: $87-93$

David P, Delay B, Berthou P, Jarne P (1995) Alternative models for allozyme-associated heterosis in the marine bivalve Spisula ovalis. Genetics 139:1719-1726

Diehl WJ, Gaffney PM, McDonald JH, Koehn RK (1985) Relationship between weight-standardized oxygen consumption and multiple-locus heterozygosity in the mussel, Mytilus edulis. In: Gibbs PE (ed) Proc 19th Eur Mar Biol Symp. Cambridge University Press, Cambridge, p 529-534

Gaffney PM (1990) Enzyme heterozygosity, growth rate, and viability in Mytilus edulis: another look. Evolution 44: $204-210$

Gardner JPA (1994) The structure and dynamics of naturally occurring hybrid Mytilus edulis Linnaeus, 1758 and Mytilus galloprovincialis Lamarck, 1819 (Bivalvia: Mollusca) populations: review and interpretation. Arch Hydrobiol (Suppl) 99:37-71

Gartner-Kepkay KE, Zouros E, Dickie LM, Freeman KR (1983) Genetic differentiation in the face of gene flow: a study of mussel populations from a single Nova Scotian embayment. Can J Fish Aquat Sci 40:443-451

Goudet J (1996) Fstat (Version 1.2)-a computer program to calculate F-statistics. J Hered 86:485-486
Goudet J, Raymond M, De Meeûs T, Rousset F (1996) Testing differentiation in diploid populations. Genetics 144: $933-1940$

Guo SW, Thompson EA (1992) Performing the exact test of Hardy-Weinberg proportions for multiple alleles. Biometrics 4:361-372

Hawkins AJS, Bayne BL, Day AJ (1986) Protein turnover, physiological energetics and heterozygosity in the blue mussel, Mytilus edulis: the basis of variable age-specific growth. Proc R Soc Lond Ser B 229:161-176

Hilbish TJ, Koehn RK (1985) The physiological basis of natural selection at the LAP locus. Evolution 39:1302-1317

Holm S (1979) A simple sequentially rejective multiple test procedure. Scand J Stat 6:65-70

Johnson MS, Black R (1984) The Wahlund effect and the geographical scale of variation in the intertidal limpet Siphonaria sp. Mar Biol 79:295-302

Karl SA, Avise JC (1992) Balancing selection at allozyme loci in oysters: implications from nuclear RFLPs. Science 256: $100-102$

King TL, Ward R, Zimmerman EG (1994) Population structure of Eastern Oysters (Crassostrea virginica) inhabiting the Laguna Madre, Texas, and adjacent bay systems. Can J Fish Aquat Sci 51:215-222

Koehn RK (1978) Physiology and biochemistry of enzyme variation: the interface of ecology and population genetics. In: Brussard P (ed) Ecological genetics: the interface. Springer, New York, p 51-72

Koehn RK, Mitton JB (1972) Population genetics of marine pelecypods. I. Ecological heterogeneity and evolutionary strategy at an enzyme locus. Am Nat 106:47-56

Koehn RK, Milkman R, Mitton JB (1976) Population genetics of marine pelecypods. IV. Selection, migration and genetic differentiation in the blue mussel Mytilus edulis. Evolution 30:2-32

Koehn RK, Newell RIE, Immermann F (1980) Maintenance of an aminopeptidase allele frequency cline by natural selection. Proc Natl Acad Sci USA 77:5385-5389

Lewis RI, Thorpe JP (1994) Temporal stability of gene frequencies within genetically heterogeneous populations of the queen scallop Acquipecten (Chlamys) opercularis. Mar Biol 121:117-126

Louis EJ, Dempster ER (1987) An exact test for Hardy-Weinberg and multiple alleles. Biometrics 43:805-811

Manly BFJ (1985) The statistics of natural selection. Chapman \& Hall, London

MCDonald JH, Siebenaller JF (1989) Similar geographic variation at the LAP locus in the mussel Mytilus trossulus and M. edulis. Evolution 43:228-231

Mclonald JH, Seed R, Koehn RK (1991) Allozymes and morphometric characters of three species of Mytilus edulis in the Northern and Southern Hemispheres. Mar Biol 111. $323-333$

Minchinina SR, Rebordinos L (1997) Genetic differentiation in marine and estuarine natural populations of Crassostrea angulata. Mar Ecol Prog Ser 154:167-174

Mitton JB, Koehn RK (1973) Population genetics of marine pelecypods. III. Epistasis between functionally related isoenzymes of Mytilus edulis. Genetics 73:487-496

Pasteur N, Pasteur G, Bonhomme F, Catalan J, Britton-Davidian J (1988) Practical isozyme genetics. Ellis Horwood Ltd, Chichester

Quesada H, Beynon CM, Skibinsky DOF (1995a) A mitochondrial-DNA discontinuity in the mussel Mytilus galloprovincialis LMK - Pleistocene vicariance biogeography and secondary intergradation. Mol Biol Evol 12:521-524

Quesada H, Zapata C, Alvarez G (1995b) A multilocus dis- 
continuity in the mussel Mytilus galloprovincialis: the interaction of ecological and life-history factors. Mar Ecol Prog Ser 116:99-115

Quignard JP, Zaouali J (1980) Les lagunes périméditerranéenne. Bibliographie ichthyologique annotée. Première partie: Les étangs français de Canet à Thau. Bull Off Nat Pêch Tunis 4:293-360

Raymond M, Rousset F (1995) GENEPOP (Version 1.2): population genetics software for exact tests and ecumenicism. J Hered 86:248-249

Raymond $M$, Väänto RL, Thomas F, Rousset F, De Meeûs T, Renaud F (1997) Heterozygote deficiency in the mussel Mytilus edulis revisited. Mar Ecol Prog Ser 156:225-237

Rice WR (1989) Analyzing tables of statistical tests. Evolution 43:223-225

Rousset F, Raymond M (1995) Testing heterozygote excess and deficiency. Genetics 140:1413-1419

Sanjuan A, Zapata C, Alvarez G (1994) Mytilus galloprovincialis and $M$. edulis on the coasts of the Iberian peninsula. Mar Ecol Prog Ser 113:131-146

Editorial responsibility: Otto Kinne (Editor), Oldendorf/Luhe, Germany
Singh SM, Green RH (1984) Excess of allozyme homozygosity in marine molluscs and its possible biological significance. Malacologia 25:569-581

Ter Braak CJF (1986) Canonical correspondence analysis: a new eigenvector technique for multivariate direct gradient analysis. Ecology 67:1167-1179

Ter Braak CJF (1987) CANOCO - a Fortran program for canonical community ordination. Microcomputer Power, Ithaca, New York, USA

Ter Braak CJF (1995) Canonical correspondence analysis and related methods in aquatic ecology. Aquat Sci 55: 255-289

Weir BS, Cockerham CC (1984) Estimating F-statistics for the analysis of population structure. Evolution 38:1358-1370

Wright S (1965) The interpretation of population structure by $F$-statistics with special regard to systems of mating. Evolution 19:395-420

Zouros E, Foltz DW (1984) Possible explanations of heterozygote deficiency in bivalve molluscs. Malacologia 25: $583-591$

Submitted: June 22,1998; Accepted: November 11, 1998 Proofs received from author(s): February 26, 1999 